\title{
Pan-PIM Kinase Inhibitor AZD1208
}

National Cancer Institute

\section{Source}

National Cancer Institute. pan-PIM Kinase Inhibitor AZD1208. NCI Thesaurus. Code C99380.

An orally available, small molecule inhibitor of PIM kinases with potential antineoplastic activity. Pan-PIM kinase inhibitor AZD1208 inhibits the activities of PIM1, PIM2 and PIM3 serine/threonine kinases, which may result in the interruption of the G1/S phase cell cycle transition, thereby causing cell cycle arrest and inducing apoptosis in cells that overexpress PIMs. The growth inhibition of several leukemia cell lines by this agent is correlated with the expression levels of PIM1, which is the substrate of STAT transcription factors. PIM kinases are downstream effectors of many cytokine and growth factor signaling pathways and are upregulated in various malignancies. 